\title{
Insect Cardioactive Neuropeptides: Peptidergic Modulation of the Intrinsic Rhythm of an Insect Heart Is Mediated by Inositol 1,4,5- Trisphosphate
}

\author{
Nathan J. Tublitz \\ Institute of Neuroscience, University of Oregon, Eugene, Oregon 97403
}

\begin{abstract}
The beat frequency of the myogenic heart of the tobacco hawkmoth, Manduca sexta, markedly increases at adult emergence in response to 2 blood-borne peptide neurohormones, known as the cardioacceleratory peptides $\left(\mathrm{CAP}_{1}\right.$ and $\mathrm{CAP}_{2}$ ). Three independent lines of evidence are presented supporting the hypothesis that the CAPs exert their cardiostimulatory effects on the insect myocardium through a change in the intracellular levels of inositol 1,4,5-trisphosphate $\left(\operatorname{InsP}_{3}\right)$. I show that (1) Ins: $\mathrm{P}_{3}$ levels increase in response to $\mathrm{CAP}_{2}$ in a timely fashion, (2) exogenous application of InsP $\mathrm{P}_{3}$ mimics the effects of $\mathrm{CAP}_{2}$ application, and (3) a blocker of InsP ${ }_{3}$ metabolism inhibits the effect of $\mathrm{CAP}_{2}$. These results provide strong support for the hypothesis that InsP $_{3}$ is likely to be the second messenger in the regulation of heart beat activity by $\mathrm{CAP}_{2}$. Besides establishing the nature of the signaling system between $\mathrm{CAP}_{2}$ and the heart, these data also identify a novel role for InsP ${ }_{3}$, namely, the control of contraction frequency in a myogenic muscle. Given the widespread distribution of cellular systems employing Ins $P_{3}$ as a second messenger, it is suggested that Ins $P_{3}$ may also be involved in the long-term regulation of rhythmic activity in other spontaneously contractile muscles and endogenously active cells.
\end{abstract}

Since the pioneering work of Sutherland and his coworkers in the 1950 s, research into the cellular mechanisms underlying receptor-mediated signal transduction has identified the pivotal role played by certain cytoplasmic factors in the transfer of information from the plasma membrane to the internal milieu (Sutherland, 1972; Krebs and Beavo, 1979). Much effort has gone into identifying these factors, or second messengers, resulting in a vast compendium of information concerning the physiological functions of the most ubiquitous of these molecules, cyclic AMP, cyclic GMP, and calcium. Recent research has identified another second-messenger system, involving metabolites of the membrane phospholipid phosphatidylinositol, that is now well documented in a variety of neural and nonneural tissues (Berridge, 1984, 1987; Berridge and Irvine, 1984). Numerous studies have firmly established that hydrolysis of

\footnotetext{
Received Feb. 12, 1988; revised Mar. 25, 1988; accepted Mar. 25, 1988.

I wish to thank Mr. J. P. Heslop and Dr. C. W. Taylor for technical advice regarding the inositol phosphate assays. I am grateful to Ms. D. Brink and Drs. M. A. N. Duker, J. S. Eisen, D. Kimble, and P. M. O'Day for their critical comments on this manuscript. This research was supported by NIII Grant NS24613.

Correspondence should be addressed to Dr. Nathan J. Tublitz at the above address.

Copyright (C) 1988 Society for Neuroscience $0270-6474 / 88 / 114394-06 \$ 02.00 / 0$
}

membrane-associated phosphotidylinositol 4,5-bisphosphate increases the cytoplasmic levels of the water soluble second messenger, inositol 1,4,5-trisphosphate ( $\left.\mathrm{Ins}_{3}\right)$ (Hokin and Hokin, 1951; Berridge, 1984, 1987; Berridge and Irvine, 1984), which appears to control many cellular processes (Streb et al., 1983; Fein et al., 1984; Irvine et al., 1984; Prentki et al., 1984; Kuno and Gardner, 1987; Sugiyami et al., 1987). Ins $\mathrm{P}_{3}$ has becn implicated in the coupling of electrical excitation with mechanical contraction in both smooth and skeletal muscle (Suematsu et al., 1984; Somlyo et al., 1985; Vergana et al., 1985; Volpe et al., 1985; Walker et al., 1987). Little is known, however, about other physiological functions of $\mathrm{InsP}_{3}$ in muscle, particularly in cardiac and other endogenously active muscles. To investigate the physiological relevance of phosphatidylinositol metabolism in rhythmically active muscle, I have utilized an invertebrate preparation, the myogenic insect heart, because much is already known about its physiology and modulation by neurally derived peptides (Tublitz et al., 1986). My colleagues and I have previously shown that the myogenic heart from the tobacco hawkmoth, Manduca sexta, is regulated by 2 endogenous neuropeptides, the cardioacceleratory peptides (CAPs) (Tublitz and Truman, 1985a, b; Tublitz and Evans, 1986). Both CAPs are synthesized by 8 individually identified neurosecretory cells that are segmentally iterated in each ganglion of the ventral nerve cord in the moth (Tublitz and Truman, 1985c, d). The CAPs are released from peripherally located neurosecretory terminals directly into the hemolymph, where they act directly on the cardiac musculature to cause a marked and physiologically important elevation in heart rate in vivo (Tublitz and Truman, 1985b; Tublitz and Evans, 1986).

The purpose of these experiments was to identify the mechanism of action of the CAPs on the Manduca heart. This paper presents several independent lines of evidence supporting the hypothesis that the CAP-induced elevation in heart rate in Manduca is mediated by an increase in the intracellular levels of $\mathrm{Ins}_{3}$. This finding strongly suggests that the intracellular concentration of $\mathrm{InsP}_{3}$ is important for the control of beat frequency in endogenously rhythmic muscles and may be crucial for the long-term modulation of rhythmicity in other autoactive cells.

\section{Materials and Methods}

Experimental animals. Larvae of the tobacco hawkmoth, Manduca sex$t a$, were individually reared on an artificial diet slightly modified from that published by Bell and Joachim (1978). Animals at all developmental stages from eggs to adults were raised in a thermally and photoperiodically regulated environmental chamber. Photoperiod and thermal cycles were phase-locked and temperatures during photophase (17 hr) and scotophase ( $7 \mathrm{hr}$ ) were 27 and $25^{\circ} \mathrm{C}$, respectively. 
Heart bioassay. Heart rate was measured using an isolated Manduca heart bioassay as previously described (Tublitz and Truman, 1985a; Tublitz and Evans, 1986). In brief, a portion of the abdominal heart was removed from a pharate adult male moth, pinned into a small superfusion chamber $(250 \mu \mathrm{l})$ and attached to a force transducer (Bionix F-200 Displacement Transducer). The transducer signal was amplified 1000 -fold and fed through a simple window discriminator circuit/digital-to-analog converter to determine instantaneous heart rate, which was then recorded with a Gould 2200 pen recorder. Samples were individually pulse-applied into an open perfusion system with a $100 \mu \mathrm{l}$ Hamilton gas-tight syringe with sample volumes varying from 50 to $100 \mu \mathrm{l}$ per application.

Physiological salines and chemicals. Normal Manduca physiological saline was used in all experiments except where noted. Normal saline is defined as either (A) $65 \mathrm{mM} \mathrm{NaCl}, 33.5 \mathrm{mM} \mathrm{KCl}, 16 \mathrm{mM} \mathrm{MgCl}, 2.5$ $\mathrm{mM} \mathrm{KHCO}, 2.5 \mathrm{mM} \mathrm{KH}_{2} \mathrm{PO}_{4}, 5.6 \mathrm{mM} \mathrm{CaCl}_{2}$, and $172.9 \mathrm{~mm}$ dextrose; or (B) $65 \mathrm{~mm} \mathrm{NaCl}, 23.5 \mathrm{~mm} \mathrm{KCl}, 16 \mathrm{mM} \mathrm{MgCl}_{2}, 5 \mathrm{~mm}$ PIPES (dipotassium salt; Sigma Chemicals), $5.6 \mathrm{mM} \mathrm{CaCl}_{2}$, and $172.9 \mathrm{~mm}$ dextrose. The final saline was adjusted to $\mathrm{pH} 6.7$ using concentrated $\mathrm{KOH}$. These salines were used interchangeably without any noticeable change in the sensitivity, longevity, or responsiveness of the bioassay. In those experiments where $\mathrm{Li}^{+}$was required, $\mathrm{LiCl}$ was substituted for dextrose on an equimolar basis. Dimethyl sulfoxide ( $5 \%$ final concentration, vol/ vol; reagent grade, Baker Chemicals) was used to permeabilize the myocardial sarcolemma and allow various inositol phosphates to gain access to the cytoplasm. Inositol and all phosphatidylinositol metabolites tested in this study were obtained from Sigma Chemicals.

Purification of $C A P$. Abdominal portions of the ventral nerve cord were removed from pharate adults and stored at $-80^{\circ} \mathrm{C}$ for further use. A few phenylthiourea crystals were added to the frozen nerve cords to prevent melanization by endogenous tyrosinases (Williams, 1959). Tissues were thawed in a small volume of $100 \%$ methanol and homogenized in a ground glass tissue homogenizer. The homogenate was centrifuged for $5 \mathrm{~min}$ at high speed in a microcentrifuge $(12,000 \times g)$, resulting in a supernatant that was diluted $1: 1$ with double-distilled water and lyophilized until dry. Dried samples were resuspended in double-distilled water and applied to a Waters C-18 Sep-pak. Samples were eluted off the Sep-pak with increasing stepwise concentrations of acetonitrile, and $\mathrm{CAP}_{1}$ and $\mathrm{CAP}_{2}$ activities found in the $80 \%$ acetonitrile fraction were freeze-dried, resuspended, and loaded onto a reverse-phase $\mathrm{C}-18 \mathrm{col}$ umn (Spherisorb, $25 \mathrm{~cm}$ long, $5 \mu \mathrm{m}$ particle size). A linear water-acetonitrile gradient with $0.1 \%$ trifluoracetic acid (TFA) as the counterion was used to separate $\mathrm{CAP}_{1}$ from $\mathrm{CAP}_{2}$ initially. The bioactive fractions for each peptide, as determined using the heart bioassay, were collected separately and chromatographed on a second reverse-phase column (Brownlee Aquapore C-8, $22 \mathrm{~cm}, 300 \AA$ particle size) using the same gradient conditions except that the counterion was $0.1 \%$ heptafluorobutyric acid (HFBA). Bioactivity from this second run was then loaded onto a third HPLC column (Brownlee Aquapore phenyl, $22 \mathrm{~cm}, 300$ $\AA, 0.1 \%$ TFA) from which a pure sample of $\mathrm{CAP}_{2}$, as determined by optical density and mass spectroscopy, was obtained.

Inositol phosphate measurements. Individual abdominal hearts were dissected free from surrounding tissues of male pharate adults and incubated in Manduca saline containing ${ }^{3} \mathrm{H}$-inositol (Amersham) for 1 2 hr. Following phospholipid labeling, hearts were washed in saline several times. One CAP Unit ( 1 CAP unit = CAP activity in 1 pharate adult abdominal ncrve cord) of HPLC-purified $\mathrm{CAP}_{2}$ was then added to each heart. At various times after peptide addition, peptide action was stopped with $\mathrm{CHCl}_{2} / \mathrm{MeOH} / \mathrm{HCl}(6 \mathrm{M})(200: 100: 1)$, and separate organic and aqueous fractions were obtained after homogenization, vortexing, and centrifugation. The aqueous phase was washed several times with $\mathrm{CHCl}_{2}$, neutralized with $\mathrm{KOH}$, centrifuged to remove any precipitate, and loaded onto Dowex mini-columns for separation of the various inositol phosphates (Berridge, 1983). The radiolabeled inositol trisphosphates extracted from the cells were eluted by using $0.1 \mathrm{M}$ formic acid $/ 1.0 \mathrm{M}$ ammonium formate as described by Berridge et al. (1983) after an initial wash with $0.1 \mathrm{M}$ formic acid $/ 0.4 \mathrm{M}$ ammonium formate to remove Ins $1 P$ and Ins $1,4 P_{2}$ from the column matrix. Free inositol was not retained on this column, eluting with the void volume as the cell extract was loaded. Since this procedure separates molecules based on their relative charge differences, it does not distinguish between the different InsP $\mathrm{P}_{3}$ isomers; hence, InsP $\mathrm{P}_{3}$ measurements include Ins $(1,3,4) \mathrm{P}_{3}$, $\operatorname{Ins}(1,4,5) P_{3}$, and $\operatorname{Ins}(2,4,5) \mathrm{P}_{3}$. For each sample, $\operatorname{Ins} \mathrm{P}_{3}$ levels were expressed as a fraction of the total amount of ${ }^{3} \mathrm{H}$-lipids in the organic phase, as determined using standard liquid scintillation procedures.
These values were then represented as a percentage of nonstimulated control samples $(t=0)$.

\section{Results}

\section{Effect of extracellular lithium on the CAP-induced increase in} heart rate

Exposure of isolated pharate adult Manduca hearts to pulse applications of HPLC-purified $\mathrm{CAP}_{2}$ resulted in a strong and robust increase in heart rate (Fig. 1, $A$ and $B$ ). The time constant of the rising (seconds) and falling (minutes) phases were appropriate for a peptide-induced cardiac response (Tublitz and Truman, 1985a). The addition of $10 \mathrm{~mm}$ extracellular $\mathrm{Li}^{+}$produced a marked inhibition of the peptide response, reducing the magnitude of the cardioacceleration to less than $25 \%$ of the original value (Fig. 1, $A$ and $B$ ). This effect was reversible (Fig. 1), although it took about $1 \mathrm{hr}$ of perfusion in normal saline to allow the $\mathrm{CAP}_{2}$ response to recover to pretreatment levels. Other known nonpeptide cardioexcitatory substances (Tublitz and Truman, 1985a), such as the biogenic amines octopamine and 5-HT, did not elicit any change in peak heart rate when applied in $\mathrm{Li}^{+}-$ containing saline (data not shown). Of the 2 CAPs known to be present in the Manduca CNS (Tublitz and Truman, 1985a, b), only $\mathrm{CAP}_{2}$ was tested in this study.

The time course of the $\mathrm{Li}^{+}$effect is shown in Figure 2. CAP was repeatedly applied to hearts in the presence of a saline containing $10 \mathrm{mM} \mathrm{Li}^{+}$. A $30 \mathrm{~min}$ exposure to $\mathrm{Li}^{+}$had virtually no effect on the heart's ability to respond to $\mathrm{CAP}_{2}$. After $60 \mathrm{~min}$ in $\mathrm{Li}^{+}$, the cardioacceleratory effect of $\mathrm{CAP}_{2}$ was reduced by $50 \%$, and by 90 min the $\mathrm{CAP}_{2}$-elicited response was suppressed to approximately $23 \%$ of control values. Lithium treatment by itself did not affect the frequency of myocardial contractions.

\section{Effects of the CAPs and other cardioregulatory factors on intracellular InsP $P_{3}$ levels}

To assess the relationship between $\mathrm{CAP}_{2}$ and $\operatorname{InsP}_{3}$ directly, intracellular levels of InsP ${ }_{3}$ were measured before and after introduction of $\mathrm{CAP}_{2}$. Isolated abdominal hearts were labeled with ${ }^{3} \mathrm{H}$-inositol, stimulated with $\mathrm{CAP}_{2}$ for various periods, and homogenized to extract and assay $\operatorname{InsP}_{3}$ levels using the procedure described in the Materials and Methods section (Berridge, 1983). Figure 3 shows that $\mathrm{CAP}_{2}$ application induced a rapid rise in intracellular [ $\mathrm{InsP}_{3}$ ], reaching a maxium within $30 \mathrm{sec}$ after $\mathrm{CAP}_{2}$ exposure. At $30 \mathrm{sec}$, Ins $\mathrm{P}_{3}$ levels were almost $200 \%$ of basal, nonstimulated controls (time 0 ). Although the $\left[\operatorname{InsP}_{3}\right]$ remained elevated above basal levels for as long as the peptide was applied, long-term peptide application (minutes) resulted in decreased Ins $\mathrm{P}_{3}$ levels compared with the initial peak. To determine whether Ins $\mathrm{P}_{3}$ levels were altered by other cardioexcitatory factors, 5HT or octopamine was applied to hearts for $2 \mathrm{~min}$ and then extracted and measured intracellular [ $\left.\operatorname{Ins}_{3}\right]$. Both of the biogenic amines tested failed to produce detectible changes in Ins $\mathrm{P}_{3}$ levels (Fig. 4) compared with nonstimulated controls. These results demonstrate that intracellular $\mathrm{InsP}_{3}$ levels rise substantially only in response to $\mathrm{CAP}_{2}$ stimulation.

\section{Dimethyl sulfoxide permeabilizes heart cells without altering contraction frequency}

In order to test directly the response of the heart to various intracellular messengers, it was first necessary to design a procedure that would permit the selective entry of molecules from the extracellular space to the intracellular milieu without de- 
Figure 1. Effect of lithium on heartbeat frequency of the in vitro Manduca heart to pulse applications of $\mathrm{CAP}_{2} . A$, Response of a single isolated heart to $\mathrm{CAP}_{2}$ application before, during, and after application of $10 \mathrm{~mm}$ extracellular $\mathrm{Li}^{+}$. Three $100 \mu$ l samples were sequentially pulse-applied to an individual heart bioassay as described in the Materials and Methods in either normal (Control) saline or in saline $\left(\mathrm{Li}^{+}\right)$containing $10 \mathrm{mM} \mathrm{LiCl}_{2}$ made isotonic by reducing the dextrose concentration. Each test sample contained 1 CAP unit of HPLC-purified $\mathrm{CAP}_{2}$ activity dissolved in the appropriate saline. $\mathrm{CAP}_{2}$ applications are indicated by arrows. Except as noted, standard Manduca physiological saline was used throughout all experiments. $B$, Effect of $\mathrm{Li}^{+}$on the $\mathrm{CAP}_{2}$-induced increase in heartbeat frequency. Each histogram depicts the mean increase \pm SEM in heart rate following $\mathrm{CAP}_{2}$ application from at least 7 different trials on 7 different heart preparations.
A
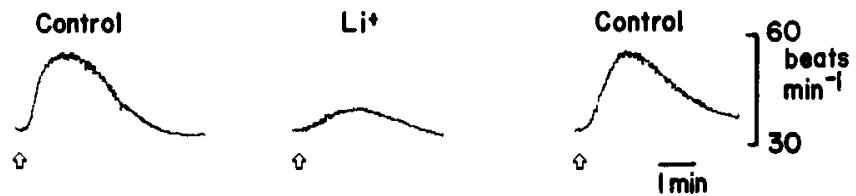

B

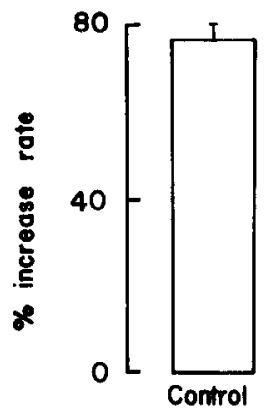

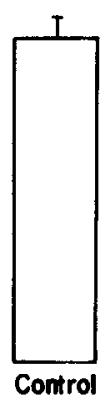

stroying the spontaneous contractility of the cardiac muscle. Over 15 different detergents, including ionic and nonionic species, were tested at a variety of concentrations ranging from $0.0001 \%$ to $>1 \%$, but none allowed the passage of putative second-messenger molecules without obliterating membrane integrity and adversely affecting the endogenous myogenic rhythm. One commonly employed method to permeabilize cell membranes is with dimethyl sulfoxide (DMSO), which allows a variety of hydrophilic substances to gain access to the intracellular milieu (Metcalf et al., 1985; Myers et al., 1986). Isolated Manduca hearts, when exposed to a physiological saline containing $5 \%$ DMSO, continued to contract rhythmically without any apparent deleterious short- or long-term effect. Neither pulse application (Fig. 5) nor long-term incubation in saline containing 5\% DMSO (Fig. 7) caused any changes in myocardial contraction frequency; the amplitude of contractions was also unaltered (data

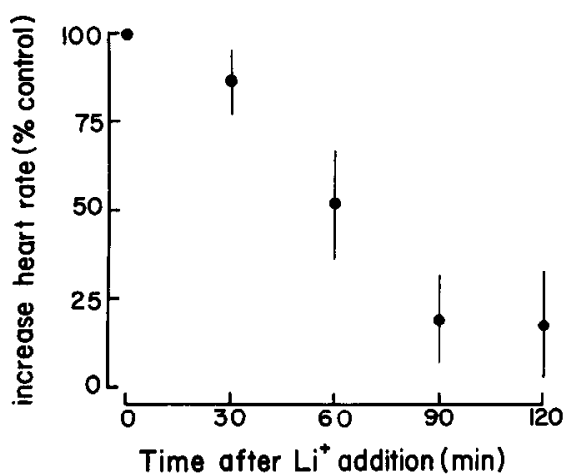

Figure 2. Time course of $\mathrm{Li}^{+}$-induced suppression of CAP cardioacceleratory activity. Isolated Manduca hearts were tested for changes in sensitivity to $\mathrm{CAP}_{2}$ application (1 CAP unit) at various times after introduction of $\mathrm{Li}^{+}$-containing saline. Each datum is expressed as the percentage increase in heart rate to $\mathrm{CAP}_{2}$ in $\mathrm{Li}^{+}$saline compared with the response in normal saline and represents the mean \pm SEM of 4 separate trials. not shown). This unusual insensitivity to high doses of DMSO permitted direct testing of the effects of $\operatorname{Ins}_{3}$ on heart rate using DMSO as a carrier.

\section{Effects of phosphatidylinositol metabolites on beat frequency in hearts permeabilized with DMSO}

To demonstrate that InsP $\mathrm{P}_{3}$ acted intracellularly, InsP $\mathrm{P}_{3}$ was applied with and without $5 \%$ DMSO. Figure 5 shows that neither DMSO nor Ins $\mathrm{P}_{3}$ alone was able to evoke a change in contraction rate of the in vitro heart, yet simultaneous application of both substances produced a marked cardioacceleration. The time course of the rising and falling phases of the Ins $\mathrm{P}_{3}$-induced response was very similar to that observed following $\mathrm{CAP}_{2}$ application (Tublitz and Truman, 1985a).

The use of DMSO to enable InsP $\mathrm{P}_{3}$ to gain entry to the cytoplasm made it possible to measure the relationship between intracellular Ins $\mathrm{P}_{3}$ concentration and heart rate accurately. Experiments in which InsP $\mathrm{P}_{3}$ was dissolved in a physiological saline containing 5\% DMSO and pulse-applied onto the heart bioassay indicated that $\operatorname{Ins}(1,4,5) \mathrm{P}_{3}$ was capable of producing a dosedependent increase in rate (Fig. 6). From the data in Figure 6, an Ins $\mathrm{P}_{3}$ threshold dosage was estimated at between 0.1 and 1.0 $\mu \mathrm{M}$, a value that is in good agreement with other published Ins $\mathrm{P}_{3}$ threshold concentrations in permeabilized and intact cells (Berridge, 1984, 1987; Berridge and Irvine, 1984). It should be noted that the actual threshold value is likely to be even lower, due to sample dilution during the bioassay procedure and because intracellular InsP $\mathrm{P}_{3}$ levels were clearly not equilibrated with the extracellular concentration.

Other putative second-messenger candidates derived from $\mathrm{InsP}_{3}$ catabolism, particularly inositol and inositol-1,4-bisphospate (Ins $1,4 \mathrm{P}_{2}$ ), failed to elicit a detectible response (Fig. 7). InsP $P_{1}$ and one of the other isomers of $\operatorname{Ins} P_{3}, \operatorname{Ins}(1,3,4) P_{3}$, also were ineffective (data not shown). The present study did not test the role of other inositol phosphates, including the other isomer of $\operatorname{Ins} \mathrm{P}_{3}, \operatorname{Ins}(2,4,5) \mathrm{P}_{3}$, nor the tetrakis- $\left(\operatorname{InsP}_{4}\right)$, pentakis$\left(\operatorname{Ins} \mathrm{P}_{5}\right)$, and hexakisphosphate (Ins $\mathrm{P}_{6}$ ) forms. 


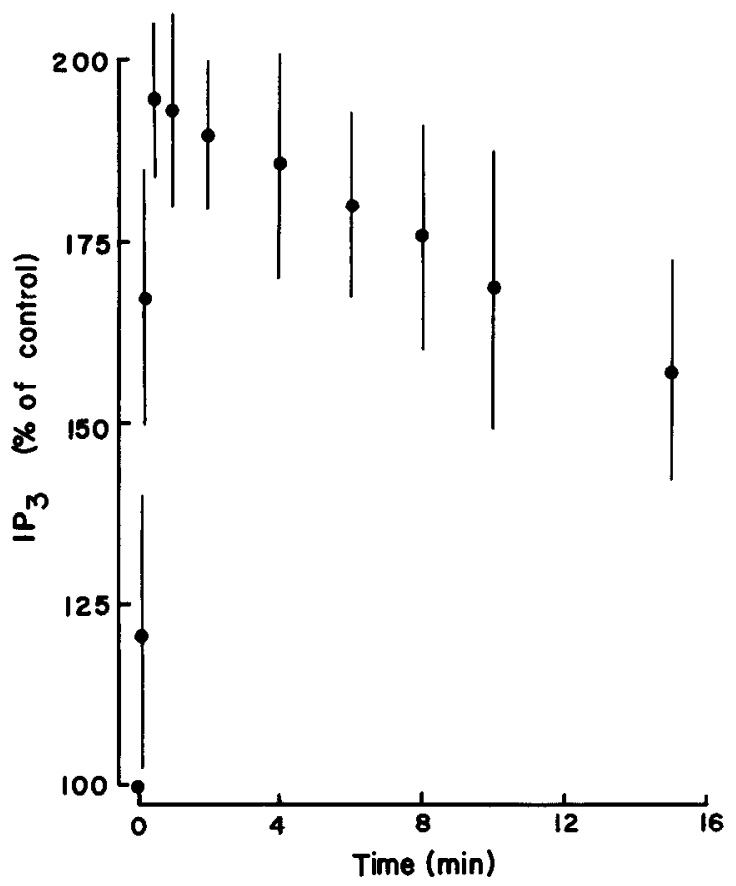

Figure 3. Time course of the $\mathrm{CAP}_{2}$-mediated increase in intracellular InsP ${ }_{3}$ levels in the abdominal portion of the pharate adult heart. Heart tissue was exposed to one unit of CAP for various durations and then extracted for $\mathrm{IsnP}_{3}$ as described in the Materials and Methods. The results of nonstimulated control samples are shown at $t=0$. For each sample, InsP $\mathrm{P}_{3}$ levels were expressed as a fraction of the total amount of ${ }^{3} \mathrm{H}$-lipids in the organic phase, as determined using standard liquid scintillation procedures. These values were then represented as a percentage of nonstimulated control samples $(t=0)$. Each time point indicates the mean change in InsP $_{3}$ levels from at least 5 different measurements and the error bar depicts \pm 1 SEM.

\section{Discussion}

Previous studies have shown that the CAPs act as cardioregulatory neurohormones, modulating heart rate during adult wingspreading behavior (Tublitz and Truman, 1985b; Tublitz and Evans, 1986). More recent evidence suggests that the CAPs are also involved in regulating heartbeat frequency during adult flight (Tublitz, unpublished observations). The main purpose of this study was to identify the mechanism of action by which the CAPs modulate heart rate in adult Manduca during these behaviors.

The only data prior to this study on the mode of action of the CAPs on the insect myocardium showed that there were no CAP-induced changes in resting levels of either cyclic AMP or cyclic GMP (N. J. Tublitz, unpublished observations), despite the fact that heart rate was altered in a dose-dependent fashion by membrane permeant analogs of cyclic nucleotides (N. J. Tublitz, unpublished observations). Based on this negative evidence, an investigation into the possible role of the inositol phosphates was initiated and comprises the basis for the current study.

One criterion that must be satisfied to establish a physiological role for a putative second messenger is to show that pharmacological manipulations that interfere with the metabolism of the second messenger also alter the physiological response elicited by the endogenous ligand. For example, it is well documented that cyclic nucleotide levels are altered by treatment with phosphodiesterase inhibitors or forskolin, both of which

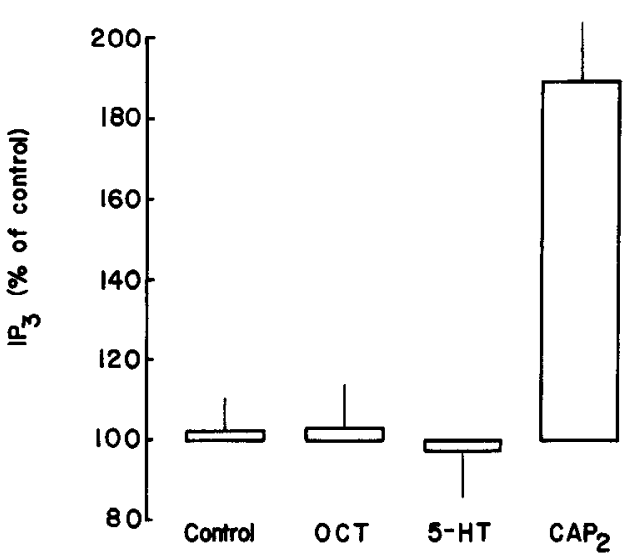

Figure 4. Effect of various cardioexcitatory factors on intracellular $\mathrm{InsP}_{3}$ levels. Isolated hearts were exposed to cardiostimulatory factors at concentrations that produced equivalent heart rate changes, i.e., equipotent doses. After a 2 min incubation period, hearts were homogenized and extracted for intracellular InsP $P_{3}$ as described in the legend to Figure 3 and in the Materials and Methods. Control, saline treated; OCT, octopamine.

act to effectively elevate cyclic AMP levels (Seamon and Daly, 1981; Evans, 1984). Previous work on the phosphatidylinositol system in rat brains, rat parotids, and insect salivary glands demonstrated that millimolar levels of extracellular lithium interfere with InsP $_{3}$ catabolism, blocking the terminal dephosphorylation of inositol 1-monophosphate to inositol by specific inhibition of the enzyme inositol 1-phosphatase (Berridge et al., 1982). This repression results in a subsequent reduction in plasma membrane levels of phosphotidylinositol and, hence, decreases $\operatorname{Ins} \mathrm{P}_{3}$ availability following receptor stimulation. Based on this work, the experiments in this paper utilized extracellular $\mathrm{Li}^{+}$as a putative blocker of InsP $\mathrm{P}_{3}$ metabolism in Manduca. Perfusion of isolated Manduca hearts with saline containing 10 $\mathrm{mM} \mathrm{Li}^{+}$substantially reduced the cardiostimulatory response to pulse applications of one of the CAPs, $\mathrm{CAP}_{2}$ (Fig. 1, $A$ and $B$ ). The time course of the $\mathrm{Li}^{+}$inhibition was quite slow, on the order of $90 \mathrm{~min}$ to reach a maximal effect. The long delay between $\mathrm{Li}^{+}$application and its maximal suppression suggests that $\mathrm{Li}^{+}$is probably acting on a biochemical process rather than directly blocking an ion channel, since the effect on the latter would be very rapid, i.e., on a time scale of seconds to a few minutes.

A second criterion in identifying a functional role for a sccond messenger is to demonstrate that ligand binding induces a change

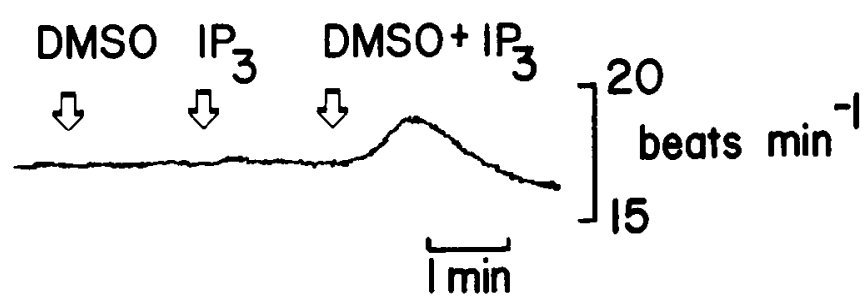

Figure 5. Response of the in vitro Manduca heart to pulse applications of InsP $\mathrm{P}_{3}$ in the presence and absence of DMSO. An isolated pharate adult heart received sequential pulse applications (100 $\mu \mathrm{l}$ each) of $5 \%$ DMSO, followed by $10^{-6} \mathrm{M}$ inositol-1,4,5-trisphosphate ( $\left.\mathrm{IP}_{3}\right)$, and then both 5\% DMSO and $10^{-6} \mathrm{M}$ inositol-1,4,5-trisphosphate $\left(\mathrm{IP}_{3}\right)$ together. Note that only the latter sample produces a detectible heart rate increase. Sample applications are indicated by the arrows. 


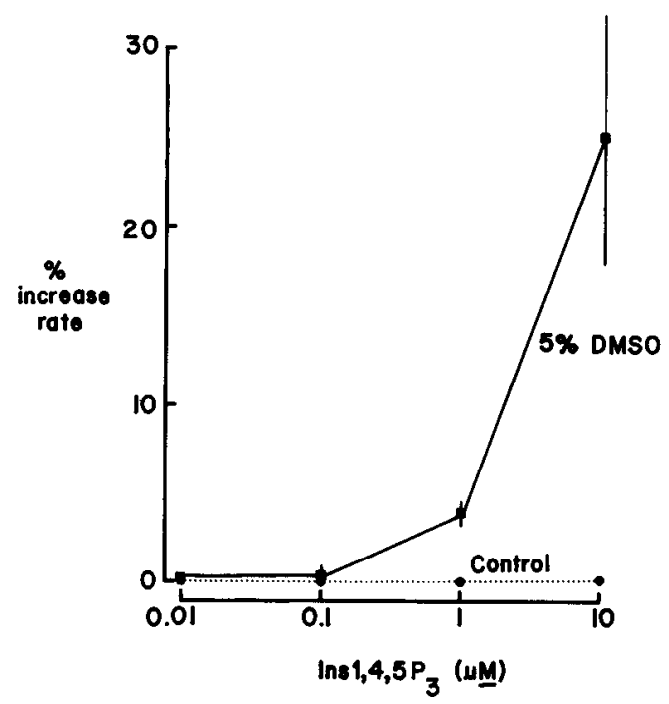

Figure 6. $\operatorname{InsP}_{3}$ dose-response curve in the presence or absence (Control) of $5 \%$ DMSO. Each point represents the mean \pm SEM of at least 9 separate determinations.

in second-messenger levels (Robinson et al., 1971; Beam and Greengard, 1976). Ins $\mathrm{P}_{3}$ levels were altered only by $\mathrm{CAP}_{2}$ (Figs. 3 and 4) and not by any other known cardioexcitatory factor with the possible exception of $\mathrm{CAP}_{1}$, which was not tested. The time course of intracellular $\mathrm{InsP}_{3}$ rises rapidly after $\mathrm{CAP}_{2}$ stimulation, reaching a peak value about $200 \%$ of unstimulated controls at $30 \mathrm{sec}$ (Fig. 4). After reaching a maximum, $\mathrm{InsP}_{3}$ levels slowly decline but remain significantly above basal levels for as long as agonist is applied. This slight drop may be due to receptor desensitization, depletion of one of the $\mathrm{InsP}_{3}$ precursor molecules such as phosphatidylinositol (PI) or the bisphosphorylated form $\left(\mathrm{PIP}_{2}\right)$, or a decrease in intracellular free calcium available for release and/or mobilization.

A third criterion that must be satisfied is to show that intracellular application of the second messenger mimics the effects of the endogenous receptor-mediated ligand. Direct application of Ins $(1,4,5) \mathrm{P}_{3}$ produced a rapid, dose-dependent elevation in heartbeat frequency that mirrored the effect of $\mathrm{CAP}_{2}$ (Figs. 57). Of all the inositol phosphates tested, only $\operatorname{Ins}(1,4,5) \mathrm{P}_{3}$ was cardiostimulatory. Interestingly, Ins $(1,3,4) \mathrm{P}_{3}$ was ineffective on the isolated Manduca heart preparation, although it is still un-

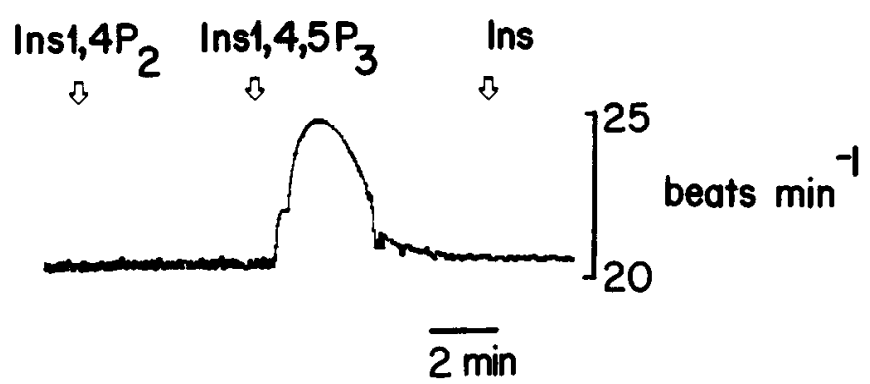

Figure 7. Effect of inositol (Ins), inositol-1,4-bisphosphate (Ins 1,4P), and inositol-1,4,5-trisphosphate (Ins 1,4,5P) on heart rate. An isolated heart was set up as described in the Materials and Methods and perfused with saline containing 5\% DMSO. All test substances were dissolved in DMSO-containing saline $(5 \%)$ and pulse applied in $100 \mu \mathrm{l}$ samples at a concentration of $10^{-5} \mathrm{M}$. Sample applications are indicated by the arrows.

\section{OUT}

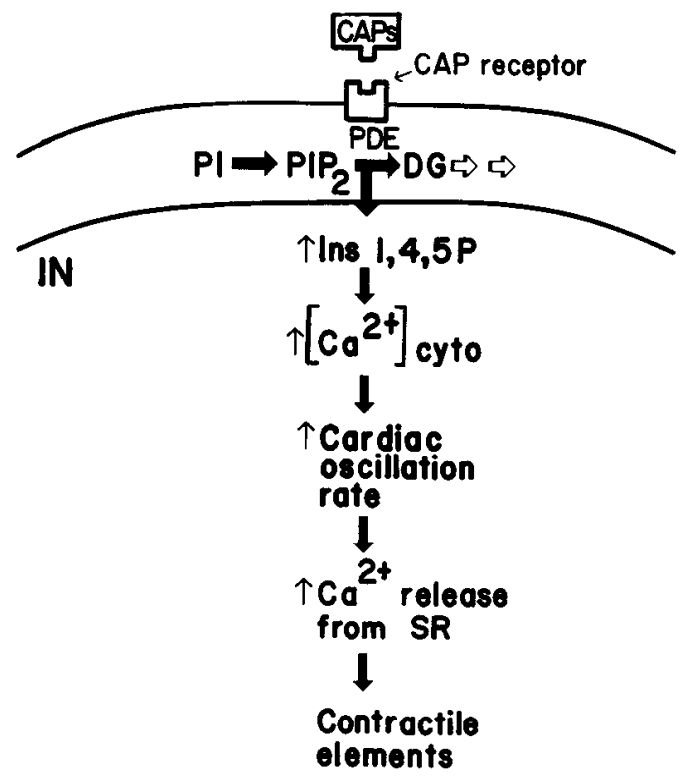

Figure 8. Model of the mechanism of action of $\mathrm{CAP}_{2}$ on the Manduca heart based upon our experimental findings. The relationship between $\mathrm{InsP}_{3}$ and intracellular free calcium is based upon preliminary data (Tublitz and Trombley, 1987) and is therefore speculative (refer to text for details).

clear exactly what physiological role is played by this inositol trisphosphate isomer (Berridge, 1987).

These results strongly support the hypothesis that $\operatorname{InsP}_{3}$ is likely to be the endogenous second messenger mediating the regulation of heartbeat activity by $\mathrm{CAP}_{2}$. That $\mathrm{InsP}_{3}$ is acting as a cytoplasmic transduction signal is no longer surprising given the ever-increasing list of cellular phenomena controlled by intracellular $\left[\mathrm{InsP}_{3}\right]$ (Berridge, 1984, 1987; Berridge and Irvine, 1984); however, the physiological consequences of elevated $\left[\mathrm{Ins}_{3}\right]$ in muscle is less well understood. It has been proposed that $\mathrm{InsP}_{3}$ is the factor in muscle by which electrical excitation is coupled to mechanical contraction, but only in smooth muscle is there good physiological evidence to lend credence to this hypothesis (Somlyo et al., 1985; Walker et al., 1987).

Unpublished observations from our lab on the relationship between $\mathrm{InsP}_{3}$ and intracellular calcium suggest that InsP $\mathrm{P}_{3}$ directly regulates free calcium levels leading to our current model concerning the regulation of heart rate by the CAPs (Fig. 8). The results in this paper support the contention that activation of the CAP receptor stimulates the hydrolysis of phosphatidyl-4,5bisphosphate $\left(\mathrm{PIP}_{2}\right)$ to cause an elevation in intracellular [Ins $\mathrm{P}_{3}$ ]. Further data suggest that CAP-induced changes in intracellular $\mathrm{InsP}_{3}$ then act to modulate tonic levels of internal free calcium, which in turn control the rate of cardiac contraction by some yet unknown mechanism (Tublitz and Trombley, 1987). The source of the $\mathrm{InsP}_{3}$-stimulated calcium pool could be of cytoplasmic, organellar, or extracellular origin, and future experiments will address this issue.

Besides establishing the nature of the signaling system between $\mathrm{CAP}_{2}$ and the heart, these data also identify a novel role for InsP $\mathrm{P}_{3}$, namely, the control of contraction frequency in a myogenic muscle. The observation that the biochemical regulation of endogenously rhythmic activity in the insect myocar- 
dium is modulated by an $\mathrm{InsP}_{3}$ - and $\mathrm{Ca}^{2+}$-dependent pathway may be of fundamental importance not only for other spontaneously contractile muscles, but also for other endogenously active cell lypes, including bursting and beating neurons.

\section{References}

Beam, K. G., and P. Greengard (1976) Cyclic nucleotides, protein phosphorylation and synaptic function. Cold Spring Harbor Symp. 40: 157-168.

Bell, R. A., and F. A. Joachim (1978) Techniques for rearing laboratory colonies of tobacco hornworms and pink bollworms. Ann. Entomol. Soc. Am. 69: 365-373.

Berridge, M. J. (1983) Rapid accumulation of inositol trisphosphate reveals that agonists hydrolyze polyphosphoinositides instead of phosphatidylinositol. Biochem. J. 212: 849-858.

Berridge, M. J. (1984) Inositol trisphosphate and diacylglycerol as second messengers. Biochem. J. 220: 345-360.

Berridge, M. J. (1987) Inositol trisphosphate and diacylglycerol: Two interacting second messengers. Annu. Rev. Biochem. 56: 159-193.

Berridge, M. J., and R. F. Irvine (1984) Inositol trisphosphate: A novel second messenger in cellular signal transduction. Nature $312: 315-$ 321.

Berridge, M. J., C. P. Downes, and M. R. Hanley (1982) Lithium amplifies agonist-dependent phosphatidylinositol responses in brain and salivary glands. Biochem. J. 206: 587-595.

Berridge, M. J., R. M. C. Dawson, C. P. Downes, J. P. Heslop, and R. F. Irvine (1983) Changes in the levels of inositol phosphates after agonist-dependent hydrolysis of membrane phosphoinositides. Biochem. J. 212: 473-482.

Evans, P. D. (1984) A modulatory octopaminergic neurone increases cyclic nucleotide levels in locust skeletal muscle. J. Physiol. (Lond.) 348: 307-324.

Fein, A., R. Payne, D. W. Corson, M. J. Berridge, and R. F. Irvine (1984) Photoreceptor excitation and adaptation by inositol $1,4,5$ trisphosphate. Nature 311: 157-160.

Hokin, M. R., and L. E. Hokin (1951) Enzyme secretion and the incorporation of ${ }^{32} \mathrm{P}$ into phosphoinositides of pancreas slices. J. Biol. Chem. 203: 967-977.

Irvinc, R. F., A. J. Letcher, D. J. Lander, and C. P. Downes (1984) Inositol trisphosphates in carbachol-stimulated rat parotid glands. Biochem. J. 223: 237-243.

Krebs, E. G., and J. A. Beavo (1979) Phosphorylation-dephosphorylation of enzymes. Annu. Rev. Biochem. 48: 923-959.

Kuno, M., and P. Gardner (1987) Ion channels activated by inositol $1,4,5$ trisphosphate in plasma membrane of human $T$-lymphocytes. Nature 326: 301-304.

Metcalf, W. K., C. B. Kimmel, and E. Schabtach (1985) Anatomy of the posterior lateral line system in young larvae of the zebrafish. $\mathbf{J}$. Comp. Neurol. 233: 377-389.

Myers, P. Z., J. S. Eisen, and M. Westerfield (1986) Development and axonal outgrowth of identified motoneurons in the zebrafish. J. Neurosci. 6: 2278-2289.

Prentki, M., T. J. Biden, D. Janjic, R. F. Irvine, M. J. Berridge, and C. B. Woldheim (1984) Rapid mobilization of calcium from rat insulinoma microsomes by inositol-1,4,5-trisphosphate. Nature 309: 562-564.

Raabe, M. (1982) Insect Neurohormones, Plenum, New York.

Raabe, M., M. Cazal, D. Chalaye, and N. de Besse (1966) Action cardioacceleratrice des organs neurohemaux perisympathetique ventraux des quelque insectes. C. R. Acad. Sci. Paris 263: 2002-2005.

Robinson, G. A., R. W. Butcher, and E. W. Sutherland (1971) Cyclic $A M P$. Academic, New York.

Seamon, K. B., and J. W. Daly (1981) Forskolin: A unique diterpene activator and cyclic AMP-generating systems. J. Cyclic Nucleotide Res. 7: 201-224.

Somlyo, A. V., M. Bond, A. P. Somlyo, and A. Scarpa (1985) Inositol trisphosphate-induced calcium release and contraction in vascular smooth muscle. Proc. Natl. Acad. Sci. USA 82: 5231-5235.

Streb, H., R. F. Irvine, M. J. Berridge, and I. Schulz (1983) Release of calcium from a nonmitochondrial intracellular store in pancreatic acinar cells by inositol-1,4,5-trisphosphate. Nature 306: 67-69.

Suematsu, E., M. Hirata, T. Hashimoto, and H. Kuriyama (1984) Inositol 1,4,5 trisphosphate releases calcium from intracellular store sites in skinned single cells of porcine coronary artery. Biochem. Biophys. Res. Commun. 120: 481-485.

Sugiyami, H., I. Ito, and C. Hirono (1987) A new type of glutamate receptor linked to inositol phospholipid metabolism. Nature 325: 531-533.

Sutherland, E. W. (1972) Studies on the mechanism of hormone action. Science 177: 193-216.

Tublitz, N. J., and P. D. Evans (1986) Insect cardioactive peptides: Cardioacceleratory peptide (CAPs) activity is blocked in vivo and in vitro with a monoclonal antibody. J. Neurosci. 6: 2451-2456.

Tublitz, N. J. and P. Q. Trombley (1987) Peptide action on insect cardiac muscle is mediatcd by inositol trisphosphatc. Soc. Ncurosci. Abstr. 13: 235.

Tublitz, N. J., and J. W. Truman (1985a) Insect cardioactive peptides: 1. Distribution and molecular characteristics of two cardioacceleratory peptides in the tobacco hawkmoth, Manduca sexta. J. Exp. Biol. 114. 365-379.

Tublitz, N. J., and J. W. Truman (1985b) Insect cardioactive peptides: II. Neurohormonal control of heart activity by two cardioacceleratory peptides in the tobacco hawkmoth, Manduca sexta. J. Exp. Biol. 114: 381-395.

Tublitz, N. J., and J. W. Truman (1985c) Identification of the neurones containing cardioacceleratory peptides (CAPs) in the ventral nerve cord of the tobacco hawkmoth, Manduca sexta. J. Exp. Biol. 116: $395-410$.

Tublitz, N. J., and J. W. Truman (1985d) Intracellular stimulation of an identified neuron evokes cardoacceleratory peptide release. Science 228: 1013-1015.

Tublitz, N. J., P. F. Copenhaver, P. H. Taghert, and J. W. Truman (1986) Peptidergic regulation of behavior: An identified neuron approach. Trends Neurosci. 9: 358-363.

Vergana, J., R. Y. Tsien, and M. Delay (1985) Inositol 1,4,5 trisphosphate: A possible chemical link in excitation-contraction coupling in muscle. Proc. Natl. Acad. Sci. USA 82: 6352-6356.

Volpe, P., G. Salviati, F. Di Virgilio, and T. Pozzan (1985) Inositol trisphosphate induces calcium release from sarcoplasmic reticulum of skeletal muscle. Nature 316: 347-349.

Walker, J. W., A. V. Somlyo, Y. E. Goldman, A. P. Somlyo, and D. R. Trentham (1987) Kinetics of smooth and skeletal muscle activation by laser pulse photolysis of caged inositol 1,4,5 trisphosphate. Nature 327: 249-252.

Williams, C. M. (1959) The juvenile hormone. I. Endocrine activity of the corpora allata of the adult cecropia silkworm. Biol. Bull. Mar. Biol. Lab. Woods Hole 116: 323-328. 